\title{
Política de gestão urbana: o caso do Município de Kilamba Kiaxi, Luanda, Angola
}

\section{Esperança Caculo da Silva}

Aeroporto Internacional Quatro de Fevereiro. Zona de Belas. Luanda. Angola. E-mail: joanitaesp@hotmail.com.

Resumo. 0 objectivo deste trabalho é desenvolver a proposta de um novo modelo de gerenciamento destinado ao tratamento de resíduos urbanos de forma sustentável, preservando o meio ambiente e gerando o trabalho e a renda para as camadas de baixo poder aquisitivo. Seu método metodológico baseia-se no reaproveitamento e recuperação de materiais descartados no lixo para retornar ao ciclo de produção, substituindo como matériasprimas naturais. Veja como o arco teórico selecciona e recicla a base. Finalize a apresentação dos resultados obtidos por países que implementam a experiência no processo de validação do modelo, incluindo o aplicável, a funcionalidade e a viabilidade que podem ser usados tanto em países do continente americano, como na Europa e no Oceano, além de outros países. Foi separado, sino também como em outros continentes com problemas semelhantes a África e Ásia.

Palavras-chave: Política pública; Gestão urbana; Resíduos sólidos; Educação ambiental; Quilamba Quiaxi.

Abstract. Urban management policy: The case of the Municipality of Kilamba Kiaxi, Luanda, Angola. The objective of this work is to develop the proposal of a new management model for the sustainable treatment of urban waste, preserving the environment and generating work and income for the low income groups. Its methodological method is based on the reuse and recovery of materials discarded in the trash to return to the production cycle, replacing them as natural raw materials. See how the theoretical are selects and recycles the base. Finalize presentation of results obtained by countries that implement the experience in the model validation process, including the applicable, functionality and feasibility that can be used in both countries of the Americas, Europe and the Ocean, and other countries. It was separated, as well as in other continents with problems similar to Africa and Asia.

Keywords: Public politics; Urban management; Solid waste; Environmental education; Quilamba Quiaxi. 


\section{Introdução}

Falar da política de gestão urbana no Município de Kilamba Kiaxi, é ir a busca de um modelo que atenda de forma adequada á gestão em resíduos sólidos, capaz de promover a sustentabilidade ambiental, social e económica e que possa ser implementada nas províncias dos países em desenvolvimento. As soluções até então encontradas, e praticadas, tratam somente de método convencional, de colectar o lixo e jogar em lugares distantes sem tratamento adequado.

Angola foi colônia de Portugal por quase de quinhentos anos, tornando-se independente apenas em 1975, depois de um período longo de guerras de libertação engendradas pelos três principais movimentos de resistência nacional, a União Nacional para Independência Total de Angola (UNITA), o Movimento Popular de Libertação de Angola (MPLA) e a Frente Nacional de Libertação de Angola (FNLA) (Castro, 2015).

Ainda de acordo com Castro (2015), de 1995 a 1997 foi elaborado o Plano de Gestão do Crescimento Urbano da Cidade de Luanda, que previa a melhoria das condições ambientais, de saneamento, acessibilidades, sistemas de drenagem e recolha de resíduos sólidos. Entretanto nunca foi implementado devido aos custos que foram avaliados como muito elevados.

O objectivo deste trabalho é desenvolver uma proposta de um novo modelo de gestão destinado ao tratamento de resíduos sólidos urbanas de forma sustentável, preservando o meio ambiente e gerando trabalho e renda para as camadas de baixo poder aquisitivo. Sua concepção metodológica baseia-se no reaproveitamento e recuperação de materiais descartados no lixo para retornar ao ciclo de produção, substituindo as matérias-primas naturais.

Trabalhos neste sentido referidos á política de gestão urbana, no caso dos resíduos sólidos urbanos no Município do Kilamba Kiaxi, são necessários para o desenvolvimento da saúde e seu reaproveitamento nas comunidades.

Assim este estudo tem como objectivo determinar a política mais apropriada no desenvolvimento da gestão dos residuos sólidos urbanos.

\section{Material e métodos}

Trata-se de um estudo qualitativo e bibliográfico para apresentar um parecer sobre a necesidade da educação ambiental no Município do Kilamba Kiaxi da Cidade de Luanda.

\section{Discussão de resultados}

\section{o lixo e a hereditariedade}

Segundo Pedrancini et al. (2011), hereditariedade é a qualidade daquilo que é hereditário, direito de sucessão, transmissão de caracteres físicos ou morais aos descendentes. 0 colonizador que governou Angola durante 500 anos, era europeu com habitados e costumes diferentes dos africanos, que não tinha a mínima noção de conceito de cidade, nem de vivencia em cidade bem estruturadas como a nossa.

Uma cidade é uma área urbana. Não há um padrão mundial que define uma cidade. Isto varia de país para pais, as Nações Unidas considera uma área urbana, uma cidade, quando esta área urbana possui mais de 20 mil habitantes (Castro, 2015).

0 português ou europeu que vive em cidades concebidas para um número determinado de pessoas até 20.000 habitantes antigamente, hoje um pouco mais, o seu conceito de família é vasto, quer dizer, que se circunscreve-se apenas em pai, mãe e filho ou filha, geralmente, um filho no máximo ou nenhum. 0 europeu viveu sempre em cidades minimamente habitáveis e bem estruturadas em termos de construção civil, saneamento 
básico, estradas e outros condimentos que uma urbe deve possuir, desde os tempos remotos da existência das primeiras sociedades, com um grau de civilização muito elevado, e o sentido de organização avançado, que primavam já pela higiene e limpeza de cada ser, a recolha e o tratamento de resíduos, e todo aquele que quisesse viver aí, tinha de se inserir no seu modus vivendo, sob o risco de ser rejeitando e tido como atrasado e incivilizado ou mesmo de porco ou imundo (Araújo, 2002).

Quanto aos africanos, desde o surgimento das primeiras sociedades organizadas do poder, começaram a viver em floresta, passando para cabanas. No século III, começaram as grandes migrações do norte para o sul do continente, hoje chamada de África Austral, motivadas pela ecologia que resultou na procura de melhores condições de habitabilidade, de terras cultiváveis para a agricultura, da pesca, da pastorícia, da segurança contra seus inimigos, etc. Evoluindo depois para a vivência em cubatas nas aldeias pequenas ou grandes, em o mínimo de estruturas em termo de saneamento do meio, em WC ou latrina, porque defecavam ao relento no capim (Ki-Zerbo, 2010).

Por lado, o sentido de família africano é mais alargada, é constituída de pai, mãe filhos, parentes (tios, avos, sobrinhos etc.), vizinhos, amigos e até conterrâneos, como citado por Dessen e Braz (2000), durante transições familiares decorrentes do nascimento de filhos. Numa residência de um africano podem viver até 20 pessoas sem constrangimento para cada membro de clã (Ogot, 2010). Viver assim, resulta em falta de condições sociais apropriadas para uma boa vida, não há capacidade de se manter por exemplo um WC em boas condições de higiene, as quantidades de alimentos a confeccionar é maior, resultando dai a produção de lixo, porque os africanos devido aos traços trazidos da vivencia dos antepassados são propensos ao lixo e como as estruturas não aguentam, ocorrem o aparecimento to esgotos entupidos e rebentados.

É importante frisar, que a Cidade de Luanda, foi concebida para 20.000 habitantes no tempo colonial, e hoje vivem aqui, cerca de 7.000.000 milhões de habitantes. Estes produzem cerca de 4.000 quatro mil toneladas de resíduos que a população da capital gera diariamente (Santos, 2015).

\section{A logistica de transporte dos residuos sólidos domiciliares (RSD)}

Ao contrário dos demais tipos de resíduos, é de responsabilidade dos municípios de gestão integrada dos resíduos sólidos domiciliares RSD gerados nos respectivos territórios, dado o facto de sua geração ser extremamente pulverizada. O País possui inúmeras realidades no que diz respeito ao manejo e disposição de RSD seja em disponibilidade e características de locais de locais de disposição, seja em termos de iniciativas de reaproveitamento. As estatísticas oficiais indicam para uma sensível evolução no quadro geral, apesar de ainda existir uma série de deficiências e, mais do que isso, disparidades regionais significativas. Para regulamentar e garantir um processo de melhoria contínua dos serviços de colecta e disposição de RSD em todos as regiões do país, com mínimos impactos ambientais e sociais, o ambiente institucional e legal tem sido recentemente modificado. Dentre os avanços mais impactantes, em nível nacional, destaca-se aprovação da Política Nacional de Saneamento Básico, em 2007, e a Política Nacional de Resíduos Sólidos, em 2010, incluisive com participação comunictária (Godfrey e Obika, 2004).

\section{O lixo e a cultura}

Sendo a cultura o conjunto de acções do meio, que asseguram a integração dos indivíduos numa sociedade, verificamos que os europeus têm uma forma mais desenvolvida na sociedade, têm princípio básico de conduta social, na inteiração com outros homens dentro da sociedade, os adulto é que deitam o lixo nos contentores em detrimento das crianças, se alguém está doente dirige-se de imediato ao hospital, come-se nos restaurantes e não nas ruas, o comércio é organizado e praticado em locais 
apropriados e devidamente asseados, têm outra forma de enterrar os seus mortos e de fazer os seus óbitos, o aspecto arquitectónico das suas cidades são tremendamente bem estruturados e organizados, bem asfaltadas, com aterro sanitários eficientes, esgotos e ruas devidamente arranjadas. A possibilidade de acumulação ou concentração de lixo é muito reduzido, devido à forma de recolha que é feita por agentes competentes na matéria.

Quanto aos negros, é bastante diferentes, vivem sempre em cubatas com estruturas pobres, o tratamento do lixo é diferente, feito de forma mais simples, cava-se um buraco e enterra-se mas quando são em grandes qualidades quantidades, são incapazes de o combater. Outro aspecto que é importante frisar, é que o negro tem a cultura de viver em grandes comunidades numa só casa, o que não é bom para a saúde, tornando-o se necessário confecção de grandes qualidades de alimentos. Comem e bebem muito geralmente, devido trabalho pesado que efectuam, logo defecam muito, expelindo grandes quantidades de fezes e urina.

\section{Desenvolvimento sustentável e a questão dos resíduos sólidos}

Desenvolvimento sustentável, expressão que recentemente parece ter emergido para se tornar presente na vida da sociedade. Todos parecem ter adoptado a sustentabilidade como uma das grandes "missões" ou "valores" que suportam a existência destes, e melhoram sua imagem. Mas, o que de facto significa o "desenvolvimento sustentável"? Além dos desastres ambientais de dimensões cada vez maiores e mais frequentes, existe ainda uma série de evidências que indicam para a necessidade de mudanças nos padrões de produção e de consumo. A demanda global por alimentos, que configura o consumo mais básico de qualquer sociedade, tem crescido de maneira significativa e tende a dobrar nos próximos 50 anos, acompanhando o aumento da urbanização e o crescimento da renda. Por outro lado, esse próprio avanço sobre os recursos naturais implica sérios desafios á capacidade da agricultura de produzir alimentos e outros produtos suficiente para abastecer a população (Rossi-Espagnet, 1983).

Na outra ponta da população está a geração de resíduos, que também acompanha o crescimento da população e da renda, e sofre influência dos hábitos de consumo. Isso implica crescente necessidade de infra-estrutura para colecta, aproveitamento, tratamento de disposição final e resíduos.

Para Brundtland (1991), o "desenvolvimento sustentável é mais que crescimento. Ele exige uma mudança no teor do crescimento, a fim de torná-lo menos intensiva de matérias-primas e energia, e mais equitativo em seu impacto".

\section{Notas sobre a evolução da preocupação ambiental}

A questão ambiental, em escala mundial, embora historicamente nova, vem adquirindo uma grande importância nas últimas décadas. Os últimos 50 anos foram marcados por profundas alterações nas relações sociais e, logo nas relações da sociedade humana com o mundo natural. Fenómenos com a contaminação do ar, das águas e dos solos, catástrofes naturais, doenças recentes, alterações no clima e nas paisagens, ameaças à biodiversidade, tornaram-se crescentes e desencadearam efeitos sobre a vida humana. As preocupações com o meio ambiente têm despertado atenções em grupos sociais, configurando o que um geógrafo denominou como uma nova "ordem ambiental internacional” (Ribeiro, 2001).

\section{Tratamento do lixo}

0 tratamento de lixo é uma etapa intermediária do sistema de limpeza urbana. Entretanto, inexiste em grande parte dos municípios, que tem os seus resíduos, quando colectados, transportados directamente às áreas de destino final, em sua maioria lixões. A 
necessidade de tratamento do lixo surge mais intensamente nas grandes estado como uma possível resposta ao que fazer com o lixo nos próximos anos já que as administrações municipais têm se defrontado com:

1. Escassez de áreas para a destinação final do lixo.

2. Disputa pelo uso das áreas remanescentes com as populações da periferia.

3. Necessidade de ampliar a vida útil do aterro em operação.

4. Disposição imprópria de resíduos infectados.

Além destas questões mais imediatas e pontuais, a discussão mundial sobre a saúde do planeta tem apontado a valorização dos componentes do lixo como uma das formas de promover a conservação de recursos.

Assim, o tratamento de lixo deve:

1. Reduzir a quantidade de lixo a ser enviado para disposição final.

2. Infernizar os resíduos infectados.

3. Recuperar os "recursos existentes no lixo.

4. Queima.

Em relação aos demais processos de tratamento, a queima de resíduos apresenta como principal vantagem a redução do volume dos resíduos, uma vez que as cinzas resultantes do processo de queima representam cerca de $25 \%$ do total queimado. Outras vantagens do processo são a recuperação da energia calorífica liberada durante a queima e, através das altas temperaturas alcançadas no forno de um incinerador (aproximadamente $850^{\circ} \mathrm{C}$ ), a neutralização da acção de vírus e bactérias que possam existir nos resíduos.

Por outro lado, no processo de queima identificam-se algumas desvantagens, como custos operacionais altos quando comparados aos custos de operação dos aterros sanitários. Sem contar que a operação dos incineradores exige mão-de-obra qualificada e tratamento específico dos gases emitidos durante o processo para evitar danos ao meio ambiente e as condições das vias de acesso no Kilamba Kiaxi (Tabela 1).

Tabela 1. condições das vias de acesso no Kilamba Kiaxi.

\begin{tabular}{|l|c|c|}
\hline Condições de acesso & Quantidade & Porcentagem \\
\hline Ruas pavimentadas & $78 \mathrm{~km}$ & $9 \%$ \\
\hline Ruas sem Pavimentos & $812 \mathrm{~km}$ & $91 \%$ \\
\hline Total & $\mathbf{8 9 0 ~ k m}$ & $\mathbf{1 0 0 \%}$ \\
\hline Passeios com pavimentos & $49 \mathrm{~km}$ & $5 \%$ \\
\hline Passeios sem pavimentos & $29 \mathrm{~km}$ & $4 \%$ \\
\hline Ruas sem passeios & $812 \mathrm{~km}$ & $91 \%$ \\
\hline Total & $\mathbf{8 9 0} \mathbf{~ k m}$ & $\mathbf{1 0 0 \%}$ \\
\hline
\end{tabular}

\section{O lixo e meio físico}

Luanda é uma cidade que está situada a sul do equador, mais concretamente no hemisfério sul. A cidade possui o clima tropical seco, muito quente, com duas estações anuais, nomeadamente, a estação quente ou seca, de maior, 9 meses, que vão de 15 de Agosto ao 14 de Maio, e a estação húmida ou cacimbo de 3 meses de duração, que vai de 15 de Maio ao 14 de Agosto do ano seguinte. 0 clima é influenciado pela corrente fria de 
Benguela, com níveis de pluviosidade bastante elevados e a cidade é banhada pelo Oceano atlântico.

É uma cidade cosmopolitana, onde podemos encontrar vários tipos de pessoas de todas as partes do mundo, mas habitada maioritariamente por indivíduos de raça negra, que migraram do interior do pais ou nas zonas rurais, devido a guerra que assolou o pais durante 30 anos, e dos povos dos países africanos limítrofes de Angola. Vê-se logo que não têm preparação para viver em cidades como esta, que foi construída para brancos já habituas ao modus habitar de citadinos.

Devidos ao intenso calor que se faz sentir em Luanda na estação quente, e a existências de extensas praias em toda a costa atlântica, muito bonitas por sinal, leva os citados a deslocarem-se para esses lugares a fim de se refrescarem com as frias águas do mar, provocando grandes concentração de pessoas, principalmente de mulheres que geralmente andam de barriguinha atraindo por isso muitos cavalheiros para um bom convívio, que carregam consigo variadíssimos utensílios de recreação com latas de cerveja, sacos de plástico, guardanapos de papel, comestíveis e outros, que dai resultam na produção de enorme qualidades de lixo nessas zonas.

Também encontramos na Cidade de Luanda, vários recintos de recreação como dancings, discotecas, parques de diversão, as famosas tardes quentes de caldos realizado nos quintais, maratonas criadas pelas estruturas do governo para comemorar efemérides, que são acompanhas das de boa música, muita cerveja geralmente em lata, e comestíveis, como churrascos, batata frita em sacos, grelhados etc. Que provoca grande concentração de pessoas que afluem a estes lugares, resultando desta actividade também na produção de muito lixo, por falta de hábitos de higiene das pessoas e de uma boa gestão por parte do governo na recolha dos resíduos quer sólidos ou líquidos.

\section{0 papel da colecta selectiva e da triagem de RSU}

0 processo de triagem de RSU pode ser significativamente facilitado quanto os resíduos são colectados já separados de alguma forma. Esse tipo de colecta, chamado de "colecta selectiva", pode ser considerado, portanto, a primeira etapa do processo de reutilização dos resíduos. Dessa forma, a sociedade é o primeiro grupo de agentes que pode, eventualmente, estar envolvido no contexto.

O serviço de colecta selectiva pode ser realizado pelos próprios administradores municipais, por empresas prestadoras de serviço contratadas pelos administradores, ou por instituições interessadas directamente nos resíduos recicláveis (associações de captadores, cooperativas etc.). É importante destacar que a colecta não necessariamente precisa ser selectiva para que os resíduos sejam significativamente maior na triagem, mas não deve ser descartada para eventuais projectos de reutilização, uma vez que pode haver uso - especialmente para queima e geração de energia - do resíduo não completamente tirado (apenas com a exclusão de algumas produtos que não poderiam ser queimados por questões de contaminação ambiental).

Os resíduos criados podem seguir destinos diversos, basicamente, compostagem (para os orgânico), reciclagem (plásticos, metais, vidros etc.) e geração de energia (cremação). Alguns resíduos, como lixo hospitalar, por exemplo, necessariamente precisam ser queimados por questões sanitárias.No caso de a reciclagem, compostagem ou queima acontecer no próprio local da triagem, pode-se, limite, entender que essa etapa ficaria suprimida.

Além da colecta informal (pelos chamados "captadores"), a operação em usinas de triagem é a etapa do processo de reutilização que absorve contingente significativo de trabalhadores, responsáveis pelo processo de triagem.

Um aspecto que pode ser relevante para a decisão de investimento em projectos de reutilização de RSU é a existência de iniciativas originadas da cooperação de mais de um município. Tais iniciativas podem configurar-se como alternativas interessantes pela 
maior oferta de resíduos, bem como pela maior importância sócio económica ao integrar mais de uma localidade geográfica ofertante desses materiais.

Tabela 2. Ruas e acessos geralmente acidentados não pavimentados e sem passeios.

\begin{tabular}{|l|c|}
\hline Serviços I & Necessidade \\
\hline Varredura de Ruas e Passeios & Não \\
\hline Lavagem de Ruas e Passeios & Não \\
\hline Capina e Corte de Relva & Não \\
\hline Varredura de Feiras e Locais de Eventos & Não \\
\hline Limpeza de Praias & Sim \\
\hline Recolha Dirigida e Transporte de Resíduos & Sim \\
\hline Recolha Contentorizada e Transportes de Resíduos & Sim \\
\hline
\end{tabular}

\section{0 lixo e as relações sociais}

O homem, é por natureza um ser social, o que o leva a viver em conjunto, respeitosamente, reciprocamente, baseando a sua vida na solidariedade e na divisão do trabalho social, fazendo existir um elenco de princípios ou regras, que pautam as condutas humanas numa determinada sociedade.

Nesta inteiração social, observamos que os homens brancos quando se juntam para conviver, sabem distinguir o trigo do joio, quer dizer, que os princípios e as regras de convivência social, são salvaguardadas com eficácia, se juntam para recrear no verdadeiro sentido da palavra. Por exemplo, no óbito do europeu, não há concentração de lixo, porque ninguém dorme em casa do infortúnio, o corpo é conservado na morgue para o dia do funeral, que é preparado a partir de uma capela próxima do hospital, onde se efectua o velório rumo ao cemitério, para os funerais do defunto. Durante o velório, serve-se apenas café e chá aos familiares e amigos. Geralmente o funeral dura um a duas horas pelo que se segue o funeral. Após o funeral, o óbito acaba e cada um vai para a sua casa e toma uma vida normal. Pele que acabamos de exemplificar, pode verificar, que há pouquíssima produção de lixo, talvez dos resíduos do chá e café que são depositados em locais apropriados.

Com os negros já não é assim. Um óbito de negro é uma grande festa, canta-se dança-se, bebe-se, desde o dia em que se anuncia o desaparecimento físico de alguém, os familiares e parentes, assim também como as pessoas mais próximos, deixam o seu habitante para se fixarem na casa do defunto, e muitas vezes com respectivas famílias durante muito tempo. Devido aos factores já enumerados acima, como o comer muito, defecar muito, casas concebidas para um numero determinado de pessoas, e ser habitada nessas circunstâncias por mais de 50 pessoas, sem duvida alguma, como as estruturas criadas não aguentam, e porque não foram assim concebidas, torna o local propenso ao aparecimento de muito lixo, porque são uns a comer, outros a beber, outros ainda a cozinhar (comidas pesadas como funge, feijão, mandioca, jinguba etc.), e os resíduos da preparação dos alimentos e dos restos dos alimentos cozinhados, tornam-se em autênticos lixos, sem duvida alguma, uma tradição muito complicada e difícil dos negros africanos ou mesmo dos angolanos.

Como estamos a falar do lixo na cidade de Luanda, generalizando-o com o lixo na sociedade dos negros, podíamos apontar outros factores, porque são vários os que concorrem para o aparecimento deste fenómeno social, não queremos deixar de salientar que, os negócios nas ruas da cidade feita por zungueiros e ambulantes, as praças da noite, a faltam de mictórios para os citadinos fazerem as necessidades quer maiores com 
menores, os miúdos de rua, os vira latas, os mercados paralelos sem as mínimas condições para a prática do comércio, e de higiene são também factores determinantes para a existência de muito lixo.

\section{Resíduos: de problema a oportunidade}

Para Ribeiro e Morelli (2009), entre os grandes problemas associados à existência dos resíduos sólidos está a iminência da ocorrência de acidentes ambientais. Estes acidentes podem se manifestar de diversas formas, envolvendo: descarte de resíduos ou de produtos químicos em vias públicos, disposição indevida sob o solo, bem como o armazenamento inadequado destes em indústrias, o que coloca em risco a saúde pública e o meio ambiente.

O resíduo industrial é um dos maiores responsáveis pelas agressões fatais ao ambiente. Nele estão incluídos produtos químicos (carbureto, pesticidas, solventes), metais (mercúrio, cádmio, chumbo) e solventes químicos que ameaçam os ciclos naturais dos locais onde são despegados. Os resíduos sólidos são amontoados e enterrados; os líquidos são despejados em rios e mares; os gases são lançados no ar, Assim, a saúde do ambiente e, consequente, dos seres que nele vivem, torna-se ameaçada, podendo levar a grandes tragédias.

\section{Vantagens e desvantagens de colecta selectiva de lixo}

Para Camarotti e Spink (2003), a colecta selectiva é um mecanismo ou uma alternativa ecológica ou ambiental que desvia o lixo ser destinado para aterros sanitários ou leixões para ser reciclado. 0 fundamento deste processo é a separação, pela população, dos materiais recicláveis (papéis, vidros, plásticos e matarias) do restante do lixo, que é jogado em aterros ou usinas de compostagem.

A colecta selectiva apresenta uma série de vantagens que trazem resultados positivos inestimáveis, tais com a preservação da paisagem, da economia de recursos naturais e diminui o impacto ambiental de lixões e aterros; permite a geração de trabalho e renda na medida em que os catodores organizam em torno de uma associação ou cooperativa autogestionária para colectar, separar, comprar e comercializar o material reciclável, ajuda a resgatar a cidadania através do processo de participação considerado como instrumento fundamental para que o sistema funcione; permite a reduzir gastos com a limpeza urbana e investimentos em novos aterros; apoia as economias locais, contribuindo para o desenvolvimento social sustentável dos municípios; permite articulações com captadores, empresas, associações ecológicas, escolas, sucateiros, etc., e contribui para mudar valores e atitudes individuais para com o ambiente, incluindo a revisão de hábitos de consumo, ou para mobilizar a comunidade e fortalecer o espírito de cidadania; possibilita a aproximação entre o poder público e a população; e contribui positivamente para a imagem do governo e dos municípios.

\section{Desvantagens de colecta selectiva de lixo}

No entanto, o custo de operação de colecta selectiva é apontado por alguns autores como prejudicial. Isso pode ser verificado a partir da comparação entre a soma dos custos de capital (planeamento, projecto, instalações de ar condicionado, veículos etc.) e dos custos de operação/ manutenção (recursos humanos, água, energia, combustíveis, serviços de terceiros divulgação etc.) com a soma dos benefícios económicos redução dos custos de transferências e destino final), benefícios sociais (aumento do número e empregos directos e indirectos) e a obtenção de receita com a venda dos materiais recicláveis. Esses quantitativos, segundo Lages (2001), tendem a apresentar resultados negativos quando comparados á colecta convencional. Por outro lado, ao se realizar a comparação entre os dois tipos de colecta, devem-se considerar a redução dos impactos 
ambientais envolvidos e os gastos com um futuro tratamento de áreas degradadas que justifica o emprenho em se consolidar essa prática.

Como foi dito antes, de qualquer forma, é importante notar que o objectivo da colecta selectiva não é gerar recursos, mas reduzir o volume de lixo, gerando ganhos ambientais. É um investimento no meio ambiente e na quantidade de vida. Não cabe, portanto, uma avaliação baseada unicamente na equação financeira dos gastos do Município do Kilamba Kiaxi com o lixo, que despreza os futuros ganhos ambientais, sociais e económicos da colectividade. A curto prazo, a reciclagem permite a aplicação dos recursos obtidos com a venda dos materiais em benefícios sociais e melhorias de infraestrutura na comunidade que participa do programa. Também pode gerar empregos e integrar na economia formal trabalhadores antes marginalizados, como no caso da cidade e dos município.

\section{Metodologia de fiscalização}

1. Gestão do sistema de Controlo das Viaturas das Operadoras;

2. Monitorização da Actividade dos Veículos das Operadoras;

3. Sistema de Apoio ao Cidadão;

4. Interligação do Sistema de Pesagem;

5. Relatórios.

\section{Fiscalização dos actos dos utentes e agentes comunitários}

1. Orientação e educação dos utentes para:

- Manipulação e acondicionamento dos resíduos;

- Horários e frequência de disposição dos resíduos na via pública;

- Educação ambiental.

2. Identificação das áreas de constrangimento sanitário:

- Orientação para solução sanitária;

- Comunicação a área de fiscalização em caso de teimosia.

\section{Conclusões}

Pelos aspectos que foram aqui focalizados, foi feita uma análise nos aspectos da hereditariedade. Foi analisado também que o meio físico constitui outro factor determinante para a manutenção do meio e o aparecimento de lixo, Luanda é uma cidade muito quente, os seus habitantes devido ao calor, são obrigado a ingerir muitos líquidos como bebidas alcoólicas e água, a comer bastante, e consequentemente, a terem de fazer muitas necessidades, quer menores como maiores. Também a criação de ambientes de lazer em locais secos para fugir do calor acompanhados da falta de educação em convívio urbano de muitos, faz produzir outras quantidades de lixo. Isto não acontece com os europeus, que tem um clima muito frio com quatro estações, como a Primavera, o verão, o Outono e o Inverno. De uma forma geral, o tempo de frio é maior, não sendo necessário o consumo de muitas alimentos nem líquidos, razão pela qual, os europeus são frios e limpos e não têm lixo. As suas cidades e municípios são também muito bem projectados dentro dos aspectos de engenharia de construção civil, o que dá poucas hipóteses aos cidadãos de produzirem o lixo.

Pelas razões acima evocadas, os europeus que estão muito desenvolvidos, primando suas vidas para o constante desenvolvimento das técnicas de higiene e limpeza do seu meio ambiente, não têm tempo para festas. Já os negros, não perdem nenhuma oportunidade para comer e beber, para criarem mercados de rua, paralelos, a existência de miúdos de rua, cães vira latas, gatos, óbitos prologados, etc. Para produção de grandes quantidades de lixo. E os factores determinantes que concorrem para o aparecimento deste fenómeno social, é sem dúvida a pobreza, as guerras tribais e do poder político, o atraso em todas as vertentes da sociedade, desde o social que faz com que até hoje em 
pleno século XXI, ainda continuamos a viver como se estivéssemos no tempo das cavernas, não acompanhado o ritmo das novas sociedades desenvolvidas. $O$ povo vive em autenticas selvas modernas dentro das cidades, sem princípios nem regras de conduta, cada um faz 0 que quer, deita o lixo onde quer, mija onde quer e assim vamos vivendo, porque as leis são fracas e não há medidas sérias de prevenção de combate ao lixo.

Os Municípios do Kilamba Kiaxi, têm os problemas na gestão da recolha e tratamento do lixo. 0 modelo de recolha não pode ser o mesmo para todas as zonas e bairros, porque Luanda é uma cidade atípica, é preciso fazer-se descontos aos aspectos como horários, acessos dos carros a determinas zonas, falta de iluminação e a criminalidade, para uma eficaz modelo de gestão de recolha e tratamento dos resíduos sólidos, o que não existem nas grandes sociedades europeias.

\section{Conflito de interesses}

Os autores declaram não haver conflito de interesses.

\section{Referências}

Araújo, C. V. F. O. Pai, mãe e filho - reflexões sobre família e educação na modernidade. Estilos da Clinica, v. 7, $\quad$ n. 12, p.100-111, 2002. Disponível em: <http://pepsic.bvsalud.org/scielo.php?script=sci_arttext\&pid=S141571282002000100009 >. Acessso em: 10 dez. 2019.

Brundtland, G. H. (Org.). Nosso futuro comum. 2. ed. Rio de Janeiro: FGV, 1991.

Camarotti, I.; Spink, P. (Orgs.). Governo local e desigualdades de gênero. São Paulo: Annamblume, 2003.

Castro, J. C. Configuração socioespacial como expressão de conflitos: expansão urbana de Luanda e o planejamento territorial de Angola. São José dos Campos: Universidade do Vale do Paraíba, 2015. (Dissertação de mestrado). Disponível em: <https://biblioteca.univap.br/dados/000014/00001429.pdf>. Acessso em: 10 dez. 2019.

Godfrey, S.; Obika, A. Improved community participation: Lessons from water supply programmes in Angola. Community Development Journal, v. 39, n. 2, p. 156-165, 2004. https://doi.org/10.1093/cdj/39.2.156

Ki-Zerbo, J. História geral da África, I: Metodologia e pré-história da África. 2. ed. rev. Brasília: UNESCO, 2010. Disponível em: <https://unesdoc.unesco.org/ark:/48223/pf0000190249>. Acesso em: 10 dez. 2019.

Lages, M. L. P. D. Participação da população de alto padrão de consumo na coleta seletiva de lixo: o caso de Teresina. Um estudo sobre a participação da população de alto padrão de consumo no processo de coleta seletiva nos bairros Jockey Clube e Fátima na Cidade de Teresina-PI. Recife: UFPE, 2001. (Dissertação de mestrado). Acesso em: <https://repositorio.ufpe.br/bitstream/123456789/3470/1/arquivo5369_1.pdf>. Acesso em: 10 dez. 2019.

Ogot, B. A. História geral da Africa, V: Africa do século XVI ao XVIII. Brasília: UNESCO, 2010. Disponível em: <https://unesdoc.unesco.org/ark:/48223/pf0000190253>. Acesso em: 10 dez. 2019.

Pedrancini, V. D.; Corazza, M. J.; Galuch, M. T. B. Mediação pedagógica e a formação de conceitos científicos sobre hereditariedade. Revista Electrónica de Enseñanza de las
Ciencias,
v. 10 ,
n. 1 ,
p. 109-132,
2011.
Disponível
em: 
<http://reec.uvigo.es/volumenes/volumen10/ART6_Vol10_N1..pdf>. Acesso em: $10 \mathrm{dez}$. 2019.

Ribeiro, D. V.; Morelli, M. R. Resíduos sólidos: problema ou oportunidade. Rio de Janeiro: Interciência, 2009.

Ribeiro, W. C. A ordem ambiental internacional. São Paulo: Contexto, 2001.

Rossi-Espagnet, A. Primary health care in the context of rapid urbanization. Community $\begin{array}{lllll}\text { Development } & \text { Journal, } & \text { v. 18, } & \text { n. 2, } & \text { p. 104-119, }\end{array}$ https://doi.org/10.1093/cdj/18.2.104

Santos, D. Encontro entre pobreza e moral em Luanda. Urbanização, direitos e violência. Sociedade e Estado, v. 30, n. 1, p. 99-122, 2015. https://doi.org/10.1590/S010269922015000100007 